\title{
Use of services and associated costs for young adults with childhood hyperactivity/conduct problems: 20-year follow-up
}

\author{
Francesco D'Amico, Martin Knapp, Jennifer Beecham, Seija Sandberg, Eric Taylor and Kapil Sayal
}

\section{Background}

Although childhood hyperactivity and conduct problems are associated with difficulties in adulthood, little is known about later service use or public expenditure costs in the UK.

\begin{abstract}
Aims
To describe the use of services and calculate recent (past 6 months) and early adulthood (since the age of 18 years) public expenditure costs incurred by young adults who had hyperactivity and/or conduct problems during childhood.
\end{abstract}

\section{Method}

A 20-year follow-up of a community sample of 6- to 7-yearold boys $(n=83)$ with hyperactivity only, conduct problems only, mixed hyperactivity and conduct problems, and no behaviour problems (control). Information was obtained about service use; recent (past 6 months), and early adulthood (since age 18 years) public expenditure costs were calculated.

\section{Results}

High levels of childhood conduct problems were associated with a two- to threefold increase in early adulthood costs, mainly driven by criminal justice contacts. Although the mixed problems group had the highest recent costs in terms of receipt of benefits and health and social care, they had the lowest criminal justice costs.

\section{Conclusions}

High levels of early childhood conduct problems are particularly associated with increased health, social care and criminal justice costs in adulthood.

\section{Declaration of interest}

None.
There is increasing evidence that problems related to childhood attention-deficit hyperactivity disorder (ADHD) can persist into early adulthood and that they can act as a risk factor for the development of additional problems including other psychiatric disorders, substance misuse, educational underachievement, difficulties with employment and relationships, and criminality. ${ }^{1-5}$ Findings from the USA highlight that children who have received a clinical diagnosis of ADHD use more services and incur greater costs than children without ADHD. ${ }^{6-8}$ Although a clearer picture is emerging in the UK about the recognition of and use of services by children and adolescents with hyperactivity and inattention problems, ${ }^{9,10}$ little is known about their use of services and associated costs once they enter adulthood and take on greater responsibility for initiating help-seeking.

A recent review of the US literature on the cost of illness related to ADHD has highlighted that its economic impact is about three times greater in relation to affected adults than children and adolescents. ${ }^{11}$ Most follow-up studies of ADHD into adulthood have relied on clinically referred samples. ${ }^{1-3}$ This means that children in these studies have been selected on the basis of their receipt of clinical services. Although a few studies have reported on later service use, ${ }^{3,12}$ their findings do not necessarily generalise to all children with ADHD, particularly in countries such as the UK, where the majority of affected children have not received specialist health services or a clinical diagnosis. ${ }^{13}$ These studies have also tended to focus on the receipt of mental health services rather than the wider range of healthcare, social and criminal justice services to which people with ADHD might present. A further limitation of previous work relates to the role of comorbidity. Although childhood ADHD is frequently comorbid with conduct problems, studies have not investigated the relative contributions of ADHD and conduct problems in influencing later service use and costs.
In a prospective longitudinal study spanning 20 years (from 1981-1983 to 2002-2004), we aim to describe the use of services by and calculate recent (past 6 months) and early adulthood (since the age of 18 years) public expenditure (governmental) costs incurred by young adults who had hyperactivity and/or conduct problems during childhood. We also investigate clinical and socioeconomic predictors of early adulthood costs of illness as well as employment outcomes.

\section{Method}

\section{Sample}

The sample reflects the second follow-up of a population-based cohort of 3215 6- to 7-year-old boys resident in the London Borough of Newham (a socioeconomically deprived inner-city area in the UK) who were attending mainstream (elementary) schools. ${ }^{14}$ The baseline study took place in 1981-1983 and has been described elsewhere. ${ }^{14}$ In summary, parent-rated Rutter $\mathrm{A}(2)$ and teacher-rated Rutter B(2) questionnaires were completed about the boys. ${ }^{15}$ High hyperactivity and conduct problem scores on these measures reflect symptom severity rather than corresponding to $\mathrm{ADHD}$ or conduct disorder diagnostic criteria. For the purpose of further assessment, boys with high levels of emotional problems on these measures were excluded from further study (because at the time of baseline assessment comorbid emotional problems were regarded as likely to reflect a different aetiology). On the basis of the questionnaire scores, four groups were defined at the age of 6-7 years:

(a) hyperactivity only - boys who scored high for hyperactivity on both parent and teacher questionnaires (pervasive hyperactivity) but below cut-off for conduct problems 
(b) conduct problems only - boys who scored high for conduct problems on either the parent or teacher questionnaire but did not have pervasive hyperactivity

(c) mixed problems - boys who scored above cut-off for conduct problems and had pervasive hyperactivity

(d) non-hyperactive/conduct problem control - boys who did not score high for either conduct problems or have pervasive hyperactivity.

Boys were randomly sampled from these four groups with the aim of providing roughly equal group sizes. The first follow-up of the sample was carried out when participants were aged 16-18 years. ${ }^{16}$

\section{Present follow-up study}

The second follow-up, in 2002-2004, involved interviews with participants when they were aged between 25 and 30 years. Participants were tracked using multiple methods (previously recorded addresses, electoral records and personal contacts) to reduce selection bias. Further details have been described elsewhere. ${ }^{17}$ From the sample of 120 baseline participants, $83(69 \%)$ were successfully followed up. The sample of this follow-up study includes 24 participants with hyperactivity only (63\% of the original group), 18 with conduct problems only ( $75 \%$ of the original group), 16 with mixed problems (64\% of the original group) and 25 controls ( $76 \%$ of the original group). Comparison of baseline variables at age 6-7 years revealed no meaningful differences between those who were and were not followed up. ${ }^{17}$ In the present analyses we report service use patterns and costs for the whole sample and for each of these four groups (hereafter referred to as 'baseline groups').

\section{Measures}

Baseline measures

For each participant, data on Rutter $\mathrm{A}(2)$ and $\mathrm{B}(2)$ scores were available. IQ scores were derived from assessments carried out using a short form of the WISC-R. ${ }^{18}$ Information from the baseline study about household size (number of rooms), household composition (number of people, including number of children aged under 17 years), parental perception of problems with housing, house living conditions (state of repair of the house), paternal occupational socioeconomic status and paternal recent employment status allowed the socioeconomic characteristics of the boys and their families to be described. ${ }^{14}$

\section{Outcome measures}

As part of the interview, information was gathered from participants about their use of health and social care services and contacts with the police and criminal justice system since the first follow-up (age of 16-18 years), and additionally about their use of health and social care services over the previous 6 months, using an adapted version of the Client Service Receipt Inventory (CSRI). ${ }^{19}$ The CSRI collects information on the use of a range of services and correlates well with data obtained from case registers. ${ }^{20}$ The version of the CSRI employed was based on the adult follow-up study of a clinical sample of adolescents with a depressive disorder. ${ }^{21}$ The following outcome data were collected.

Service use from the age of 18 years. Participants were asked about their use of accident and emergency (A\&E), general hospital and psychiatric out-patient department services (specialty clinic visits) and any general or psychiatric hospital in-patient admissions (stays). They were also asked whether they had been prescribed medication for anxiety, depression, psychosis or ADHD.

Police and criminal justice contacts from the age of 18 years. Participants were asked details about their contacts with the police and probation officers, arrests, appearances in court, and stays in prison or remand.

Recent service use. Participants were asked about their contacts with a range of health services in the previous 6 months including attendances at general practitioner (GP, primary care), general hospital out-patient or A\&E services, and psychiatric out-patient services.

Occupational and employment status. Participants were asked about their receipt of state welfare benefits in the previous 6 months and about their employment status and absenteeism (time off work) in the previous 12 months. For absenteeism, response categories included: none/rare, occasional (phase), occasional (throughout), frequent (phase), and frequent (throughout).

\section{Costs of use of services}

To investigate whether there were any systematic differences in average cost by baseline group, a global cost was calculated for each individual based on the services used. Health and social care-related unit costs for hospital services were obtained from National Health Service (NHS) reference costs for $2009 / 10^{22}$ and unit costs for GP visits, nurse consultations, counselling and social care support were taken from the Personal Social Services Research Unit (PSSRU) volume for 2010. ${ }^{23}$ Values for Disability Living Allowance (DLA; a state benefit for care needs related to mental or physical disability) and work (employment-related) and housing benefits (to assist with costs of accommodation rent) were obtained using averages obtainable from public sources (www.direct.gov.uk). Unit costs for court appearances and prison stays were also obtained from public sources; ${ }^{24,25}$ we did not include the victim costs of crime because our focus was on public sector costs (public expenditure).

For the purpose of the analyses, a number of assumptions were made about the services where detailed information was not available.

(a) Average cost measures were adopted for use of hospital services (average cost per admission or per follow-up outpatient attendance for England) because no specific clinical diagnosis information was available.

(b) For criminal justice services, the length of a remand or prison stay was assumed to be equal to 1 month as no specific information was available about the proportions of remand (typically shorter) and prison stays or about duration of stay. As this may reflect an underestimate, we also carried out sensitivity analyses to examine the impact of a longer estimate on the associations between baseline characteristics and follow-up costs (see Analysis). This longer estimate is based on government figures suggesting that the average length of prison stays in 2002 was about 8 months. ${ }^{26}$ However, average figures reflect the whole adult age range and data may be skewed because of outliers.

(c) Unemployment benefit values were based on the JobSeeker's Allowance (an unemployment benefit) and DLA benefits, and estimated as average values of the care component and the mobility rate. 
(d) Housing benefits were estimated using average values for the London Borough of Newham.

All costs were adjusted as necessary to 2010 prices using the government's gross domestic product (GDP) deflator. ${ }^{23}$ Costs were then pooled together in four categories: recent health and social care costs (past 6 months), recent benefits (past 6 months), early adulthood health and social care costs, and early adulthood criminal justice costs. It should be noted that benefit receipts are usually treated as 'transfer payments' in costing studies carried out from a societal perspective but they represent real costs when looking at government expenditure.

\section{Analysis}

The following analyses were carried out. We cross-tabulated the various main types of service use according to baseline group status. For continuous variables, we tested for any mean difference by group using an $F$-test for each predictor and $\chi^{2}$-tests for binary/categorical variables. A similar $F$-test procedure was used to test for differences between the four cost aggregations by baseline group.

Regression analyses were used to ascertain the association between baseline characteristics and follow-up costs. Three different specifications were implemented using generalised linear model (GLM) regressions and robust standard errors (assuming a log-link and a gamma family distribution). The first specification aimed to investigate whether baseline problems (hyperactivity, conduct problems and the hyperactivity $\times$ conduct problem interaction term) could help predict costs in early adulthood. In the second step (Model B) we adjusted for age and IQ and, in the third step (Model C), for socioeconomic baseline covariates to examine further potential associations. To make efficient use of the baseline socioeconomic variables, principal components factor analysis was used to restrict the number of covariates based on the existing correlations between the variables. ${ }^{27}$ Based on the principal components factor analysis, three factors were estimated and included in the regression analyses. The three factors were identified on the basis of the factor loadings, representing correlations between latent and manifest variables: first, household size reflecting number of rooms (factor loading $=0.52$ ), people in the household (0.82) and children aged under 17 years (0.86); second, housing problems reflecting problems with housing (0.90) and poor state of repair (0.76); and third, father's work status, reflecting father's occupational socio-economic status (0.46) and recent employment (0.92). As described above, a sensitivity analysis was also carried out to give an indication of the impact of a longer estimate of prison stays on the associations between baseline childhood characteristics and follow-up costs.

Similar regression analyses were used to explore associations between baseline characteristics (all predictor variables as in Model C above) and participants' employment outcomes (i.e. employment status and level of absenteeism) at follow-up.

For the above analyses, multiple imputation allowed the estimates to be run on the full sample. The multiple imputation process was based on the method of chained equations, ${ }^{28}$ using a number of imputations (five) that preserved the efficiency of the estimates. The results presented here are based on imputed analyses. The GLM coefficients are exponential and can be interpreted as odds ratios (compared with no/low problems) with $95 \%$ confidence intervals. As the model is exponential, the effect for the mixed problems group reflects the combination (multiplicative) of the hyperactivity $\times$ conduct problem interaction term with the main separate effects of hyperactivity and conduct problems.

\section{Results}

\section{Sample}

As shown in Table 1, there were few differences between the baseline groups apart from the Rutter A2 and B2 scores, which were used to categorise the boys in the original study. The only other notable between-group difference related to a higher number of household members in the mixed problems group.

\section{Longitudinal analyses}

The service use data present a mixed picture (Table 2). The group with mixed problems had the highest rates of contact with a GP, general out-patient and A\&E services over the 6 months before the (adult) interview. When looking at service use from the age of 18 years, an average of about 10 years, most participants had used $\mathrm{A} \& \mathrm{E}$ and general hospital out-patient services. Boys in the three behavioural problem groups were more likely to have had admissions to a general hospital than their peers in the control group. The control and hyperactivity groups were slightly more likely to have had contact with psychiatric out-patient services and received medication. Prescribed medication was mainly for anxiety or depression - none of the sample had received medication for ADHD since the age of 18 (they reached this age between 1992 and 1994). More than half the sample had contact with the police since the age of 18 years. Although the proportions currently employed were similar across groups, absenteeism was

\begin{tabular}{|c|c|c|c|c|c|}
\hline & $\begin{array}{l}\text { Control } \\
(n=25)\end{array}$ & $\begin{array}{l}\text { Hyperactive } \\
\qquad(n=24)\end{array}$ & $\begin{array}{l}\text { Conduct problem } \\
\qquad(n=18)\end{array}$ & $\begin{array}{c}\text { Hyperactive } \\
\text { \& conduct problem } \\
\qquad(n=16)\end{array}$ & $P$ \\
\hline Rutter A2 score, mean (s.d.) & $4.16(3.33)$ & $12.29(7.42)$ & $11.61(2.57)$ & $15.38(5.90)$ & $<0.001$ \\
\hline Rutter B2 score, mean (s.d.) & $9.48(5.24)$ & $15.00(6.92)$ & $10.11(4.61)$ & $16.06(4.12)$ & $<0.001$ \\
\hline Number of rooms, mean (s.d.) & $4.92(0.76)$ & $4.71(0.95)$ & $4.89(0.76)$ & $4.81(0.91)$ & 0.83 \\
\hline $\begin{array}{l}\text { Number of people in the household, } \\
\text { mean (s.d.) }\end{array}$ & $4.44(1.36)$ & $4.13(1.33)$ & $4.39(1.04)$ & $5.50(1.63)$ & 0.02 \\
\hline Number of children ( $<17$ years), mean (s.d.) & $2.28(1.37)$ & $2.67(1.27)$ & $2.44(0.92)$ & $3.13(1.45)$ & 0.21 \\
\hline Father unemployed (>3 months), $n$ (\%) & $3 / 22(14)$ & $1 / 19(5)$ & $0(0)$ & $4 / 15(27)$ & 0.10 \\
\hline $\begin{array}{l}\text { Fathers' occupational SES (semi-skilled } \\
\text { and unskilled), } n \text { (\%) }\end{array}$ & $5 / 24(21)$ & $8 / 20(40)$ & $5 / 17(29)$ & $4 / 15(27)$ & 0.57 \\
\hline Housing problems, $n(\%)$ & $3(12)$ & $6(25)$ & $1(6)$ & $4(25)$ & 0.27 \\
\hline Housing: poor state of repair, $n$ (\%) & $6(24)$ & $8(33)$ & $6(33)$ & $6(37)$ & 0.81 \\
\hline
\end{tabular}


Table 2 Follow-up characteristics by baseline group

\begin{tabular}{|c|c|c|c|c|c|}
\hline & $\begin{array}{l}\text { Control } \\
(n=25)\end{array}$ & $\begin{array}{l}\text { Hyperactive } \\
\qquad(n=24)\end{array}$ & $\begin{array}{l}\text { Conduct problem } \\
\qquad(n=18)\end{array}$ & $\begin{array}{c}\text { Hyperactive } \\
\text { \& conduct problem } \\
(n=16)\end{array}$ & $P$ \\
\hline Age, years: mean (s.d.) & $27.36(1.47)$ & $27.71(1.27)$ & $27.61(1.04)$ & $27.69(0.70)$ & 0.74 \\
\hline \multicolumn{6}{|l|}{ Service use in past 6 months (yes/no), $n(\%)$} \\
\hline GP & $15(60)$ & $12 / 22(55)$ & 7 (39) & $13(81)$ & 0.09 \\
\hline General hospital out-patient or A\&E & $4(16)$ & $4 / 23(17)$ & $1(6)$ & $5(31)$ & 0.26 \\
\hline \multicolumn{6}{|l|}{ Service use since age 18 years (yes/no), $n(\%)$} \\
\hline$A \& E$ & $12(48)$ & $15(63)$ & $12(67)$ & $10 / 15(67)$ & 0.54 \\
\hline General hospital out-patient & $16 / 22(73)$ & $17 / 23(74)$ & $11(61)$ & $12(75)$ & 0.78 \\
\hline General hospital admission & $5(20)$ & $10(42)$ & 7 (39) & $7 / 15(47)$ & 0.27 \\
\hline Psychiatric out-patient & $5(20)$ & $4(17)$ & $1(6)$ & 0 & 0.18 \\
\hline Psychiatric hospital admission & $1(4)$ & $2(8)$ & 0 & 0 & 0.66 \\
\hline Received medication for anxiety/depression & $4(16)$ & $3(13)$ & $2(11)$ & $1(6)$ & 0.83 \\
\hline Police contact since age 18 years (yes/no), $n$ (\%) & $15(60)$ & $13(54)$ & $10(56)$ & $11(69)$ & 0.81 \\
\hline \multicolumn{6}{|l|}{ Employment, $n$ (\%) } \\
\hline Employed (yes) & $22(88)$ & $19(79)$ & $15(83)$ & $13(81)$ & 0.87 \\
\hline No/rare absenteeism & $11 / 23(48)$ & $15 / 21(71)$ & 4/17 (24) & $7 / 14(50)$ & 0.03 \\
\hline
\end{tabular}

more common in the group with conduct problems (Pearson $\chi^{2}$ test, $P=0.03$ ).

\section{Public expenditure costs}

As detailed in Table 3, when considering the 6-month period immediately prior to the follow-up interview, the conduct and mixed problems groups received more income through welfare benefits than the control group, receiving on average around $\mathfrak{E} 500$ and $\mathfrak{E} 600$ respectively. The overall public expenditure costs for this 6-month period, which includes health and social care services and benefit receipts, shows that the mixed problems group had the highest overall total costs (£1299).

Looking at resource utilisation since the age of 18 years (Table $3)$, health and social care costs were similar $(P=0.79)$ across the groups, although observed costs show a difference in excess of $\mathfrak{E} 1000$ between the control group and the conduct problems group. Criminal justice costs appeared to be much higher in the conduct problems group $(£ 3561)$ than in the other groups, although this may be partially driven by a few individuals in this group with particularly intense levels of criminal activity. Related to this, the median and range values (difference between highest and lowest value) for the criminal justice costs were greatest in the conduct problem group: $£ 412$ and $£ 40602$ respectively compared with $£ 68$ and $£ 22367$ for the control group, $£ 0$ and $\mathfrak{E} 18732$ for the hyperactivity only group, and $\mathfrak{E} 0$ and $\mathfrak{E} 3339$ for the mixed problems group. In terms of total costs, individuals in the conduct problems group incurred the highest costs (£6231) and those in the mixed problems group incurred unexpectedly low values ( $£ 2549$ ), reflecting a relatively low average criminal justice cost: none of this group reported a prison stay.

\section{Predictors of costs in early adulthood}

Table 4 shows the predictors of costs since the age of 18 years. We used three different specifications to initially assess the impact of baseline group predictors on their own and then after adjustment for child-level and socioeconomic baseline characteristics. The exponential coefficients for conduct problems predicting higher costs were 3.25 in Model B and $2.63(P=0.054)$ in Model C - after adjusting for age, IQ, household size, housing problems and father's work status - with an average marginal effect for higher cost compared with no/low problems (control group) of $£ 4033$. Having high levels of childhood conduct problems incurred a two- to threefold greater early adulthood cost (although with wide confidence intervals) compared with low levels of childhood

\begin{tabular}{|c|c|c|c|c|}
\hline & $\begin{array}{c}\text { Control }(n=25) \\
\text { Mean (s.d.) }(95 \% \mathrm{Cl})\end{array}$ & $\begin{array}{l}\text { Hyperactive }(n=24) \\
\text { Mean (s.d.) }(95 \% \mathrm{Cl})\end{array}$ & $\begin{array}{l}\text { Conduct problem }(n=18) \\
\text { Mean (s.d.) }(95 \% \mathrm{Cl})\end{array}$ & $\begin{array}{l}\text { Hyperactive \& conduct problem } \\
\qquad(n=16) \\
\text { Mean (s.d.) }(95 \% \mathrm{Cl})\end{array}$ \\
\hline \multicolumn{5}{|l|}{ Past 6 months } \\
\hline Total benefits & $\begin{array}{c}68(341) \\
(-73 \text { to } 209)\end{array}$ & $\begin{array}{c}160(547) \\
(-71 \text { to } 391)\end{array}$ & $\begin{array}{c}519(1457) \\
(-206 \text { to } 1243)\end{array}$ & $611(2443)$ \\
\hline \multirow[t]{2}{*}{ Health and social care } & 694 (1829) & $442^{a}(765)$ & $413(945)$ & 689 (1160) \\
\hline & $\begin{array}{c}(-61 \text { to } 1449) \\
762(1849)\end{array}$ & $\begin{array}{l}\text { (111 to 773) } \\
609^{\mathrm{a}}(1053)\end{array}$ & $\begin{array}{l}(-57 \text { to } 883) \\
932(1822)\end{array}$ & $\begin{array}{l}(-71 \text { to } 1307) \\
1299(2994)\end{array}$ \\
\hline Total & $(-1.17$ to 1525$)$ & (154 to 1064) & (26 to 1838 ) & (-296 to 2895) \\
\hline \multicolumn{5}{|l|}{ Since age of 18 years } \\
\hline \multirow[t]{2}{*}{ Criminal justice } & 1294 (4448) & 1001 (3801) & 3561 (9511) & 539 (953) \\
\hline & $(-542$ to 3130$)$ & $(-604$ to 2606$)$ & $(-1169$ to 8290$)$ & (31 to 1047) \\
\hline \multirow[t]{2}{*}{ Health and social care } & $1563(2797)$ & 2099 (2662) & $2670(5758)$ & 2010 (2016) \\
\hline & (408 to 2717 ) & (975 to 3222) & ( -193 to 5533$)$ & (935 to 3084) \\
\hline \multirow[t]{2}{*}{ Total } & $2856(6945)$ & 3099 (4950) & 6231 (14985) & 2549 (2244) \\
\hline & $(-10$ to 5723$)$ & (1009 to 5189 ) & $(-1221$ to 13682$)$ & (1353 to 3744 ) \\
\hline
\end{tabular}




\begin{tabular}{|c|c|c|c|}
\hline & $\begin{array}{c}\text { Model A } \\
\text { Exp(b) }(95 \% \mathrm{Cl})\end{array}$ & $\begin{array}{c}\text { Model B } \\
\text { Exp(b) }(95 \% \mathrm{Cl})\end{array}$ & $\begin{array}{c}\text { Model C } \\
\text { Exp(b) }(95 \% \mathrm{Cl})\end{array}$ \\
\hline Hyperactive & $1.09(0.36-3.32)$ & $1.70(0.76-3.79)$ & $1.74(0.83-3.63)$ \\
\hline Conduct problems & $2.15(0.52-8.97)$ & $3.25 *(1.05-10.03)$ & $2.63(0.98-7.03)$ \\
\hline Hyperactive $\times$ conduct problems interaction term ${ }^{a}$ & $0.40(0.08-2.03)$ & $0.23(0.05-1.01)$ & $0.26 *(0.07-0.94)$ \\
\hline Age & - & $0.81(0.62-1.07)$ & $0.78(0.57-1.06)$ \\
\hline IQ & - & $0.98 *(0.96-0.99)$ & $0.98(0.96-1.00)$ \\
\hline Household size (factor 1) & - & - & $1.20(0.88-1.64)$ \\
\hline Housing problems (factor 2) & - & - & $0.92(0.71-1.19)$ \\
\hline Father's work status (factor 3$)^{b}$ & - & - & $1.20(0.89-1.62)$ \\
\hline Observations & 83 & 83 & 83 \\
\hline \multicolumn{4}{|c|}{$\begin{array}{l}\text { a. Aggregate (combined) coefficients for the mixed problems group are } 0.93(95 \% \mathrm{Cl} 0.33-2.64 ; P=0.90) \text { in Model } \mathrm{A} ; 1.29(95 \% \mathrm{Cl} 0.62-2.70 ; P=0.50) \text { in Model } \mathrm{B} \text { and } 1.20 \\
(95 \% \mathrm{Cl} 0.56-2.57 ; P=0.64) \text { in Model } \mathrm{C} \text {. } \\
\text { b. The higher the score, the poorer the work status. } \\
{ }^{\prime} P<0.05 \text {. }\end{array}$} \\
\hline
\end{tabular}

conduct problems. In order to assess the effect on the associations of a longer estimate of prison stays and of the individuals with particularly intense levels of criminal activity, we ran a sensitivity analysis, temporarily eliminating one individual from the conduct problems group who was an outlier in terms of number of prison stays. In the fully adjusted model, there was no evidence of change in the strengths of associations between baseline childhood characteristics and follow-up costs (online Table DS1).

High levels of baseline hyperactivity problems were associated with slightly higher costs compared with low levels of hyperactivity (1.09-1.74 times higher). The average marginal effect on costs was $£ 2118$ higher than for the control group. The exponential coefficient for the hyperactivity $\times$ conduct problems interaction term was 0.23 in Model B and 0.26 in Model C. Combining the main effects with the interaction effect for the mixed problems group, the aggregate coefficient was 1.20 for Model $C(P=0.64)$, with an average marginal effect of $£ 2208$. This suggests that, after adjusting for age, IQ, household size, housing problems and father's work status, the presence of high levels of both types of behavioural problems was associated with slightly higher early adulthood costs compared with having low levels of both types of problems. Each one-point increase in IQ was associated with a reduction in early adulthood costs $(P=0.054$ in Model $C)$. None of the derived socioeconomic factors was associated with higher costs.

\section{Relationships between baseline characteristics and employment outcomes}

Table 5 shows that none of the childhood predictor variables was associated with current employment status. After adjustment for confounders, absenteeism was weakly associated with higher IQ scores, suggesting that those with a higher IQ may be more likely to take time off work.

\section{Discussion}

Although there is now quite good evidence on the childhood costs associated with hyperactivity, ${ }^{6-8,10}$ little is known about the use of services and costs incurred by adults who had hyperactivity problems during their childhood. The 20-year follow-up study described in this paper contributes to the literature by quantifying the long-term public sector costs of childhood hyperactivity and conduct problems in a community-based non-clinical population. We found that the conduct problems group had the biggest impact on public sector costs in early adulthood, with more than half the average cost due to contacts with the criminal justice system. The total costs in early adulthood were fairly similar in the other three groups. Although the presence of baseline conduct problems appeared to reduce the likelihood of future contact with mental health services, this group also appeared to incur slightly higher early adulthood health service costs than the other groups.

After adjusting for confounders, high levels of childhood conduct problems were associated with a two- to threefold difference in early adulthood costs compared with no problems. As none of the sample in the mixed problems group had gone to prison, this group had the lowest criminal justice costs since age 18 years. However, their health and social care costs since age 18 were similar to the other groups. Similarly, police contacts were similar across the four groups, possibly because the sample consists of young men from a socioeconomically deprived innercity area. Looking at the more recent cost profiles, over the 6 months before the interview, the conduct problems group and the mixed problems group incurred much higher costs for state welfare benefits than the other two groups.

Studies of the cost consequences of mental health problems do not generalise easily from one country to another because service systems, funding arrangements and relative prices can vary considerably. The baseline study was conducted at a time when ADHD was rarely diagnosed in the UK and medication did not tend to be offered. ${ }^{29}$ National UK data from 2004 also suggest that only about a third of children and adolescents meeting criteria for ADHD were prescribed medication. ${ }^{9}$ Therefore ADHD treatment costs did not contribute to the healthcare costs described in this paper. As treatment for ADHD is associated with improved

\begin{tabular}{|c|c|c|}
\hline & $\begin{array}{l}\text { Employed } \\
\text { Odds ratio } \\
(95 \% \mathrm{Cl})\end{array}$ & $\begin{array}{c}\text { Absenteeism } \\
\text { (any level) } \\
\text { Odds ratio }(95 \% \mathrm{Cl})\end{array}$ \\
\hline Hyperactive (yes/no) & $0.55(0.10-3.04)$ & $0.29(0.08-1.05)$ \\
\hline Conduct problems (yes/no) & $0.49(0.07-3.19)$ & $2.02(0.47-8.64)$ \\
\hline $\begin{array}{l}\text { Hyperactive } \times \text { conduct problems } \\
\text { interaction term }{ }^{\mathrm{a}}\end{array}$ & $3.03(0.22-42.44)$ & $1.48(0.19-11.81)$ \\
\hline Age & $0.88(0.50-1.55)$ & $1.30(0.85-1.99)$ \\
\hline IQ & $1.02(0.98-1.07)$ & $1.04(1.00-1.09)$ \\
\hline Household size (factor 1) & $1.00(0.51-1.97)$ & $0.97(0.57-1.67)$ \\
\hline Housing problems (factor 2) & $0.60(0.35-1.05)$ & $1.02(0.58-1.82)$ \\
\hline Father's work status (factor 3$)^{b}$ & $1.87(0.84-4.19)$ & $1.39(0.79-2.43)$ \\
\hline Observations & 83 & 83 \\
\hline \multicolumn{3}{|c|}{$\begin{array}{l}\text { a. Aggregate (combined) odds ratios for the mixed problems group are } 0.81 \\
(95 \% \mathrm{Cl} 0.11-5.93 ; P=0.84) \text { in the employment model and } 0.85(95 \% \mathrm{Cl} 0.18-3.95 ; \\
P=0.84) \text { in the absenteeism model. } \\
\text { b. The higher the score, the poorer the work status. }\end{array}$} \\
\hline
\end{tabular}


outcomes ${ }^{30}$ follow-up studies of children with hyperactivity who did not receive treatment may result in higher public expenditure costs in early adulthood compared with children who did receive treatment.

A review of studies from the USA has highlighted the considerable economic impact associated with ADHD. ${ }^{11}$ From the existing literature, the most comparable findings come from a US-based population birth cohort of children with ADHD who were followed up until age 13-19 years. ${ }^{31}$ Compared with our findings, a smaller proportion of their sample had out-patient hospital appointments (41\%) and in-patient hospital admission (26\%). However, their rates of A\&E contact (81\%) were slightly higher than ours. Data from a 1970 British birth cohort study suggest that attention problems at the age of 10 years were associated with adverse employment outcomes and lower earnings in adulthood. ${ }^{5}$ In contrast, although early conduct problems were associated with later unemployment, males with conduct problems had higher earnings than males without these problems. $^{5}$

Although we did not find any adverse impact on employment in this study, our findings add to the literature by quantifying the public expenditure associated with early behaviour problems. Another study in the UK followed up a community-based sample of children from the age of 10 years until their late 20s and found that $7 \%$ of children with conduct problems had used psychiatric out-patient services in adulthood, ${ }^{32}$ similar contact rates to the conduct problems group in the present study. Children with conduct problems, even if they did not meet diagnostic criteria for a conduct disorder, incurred greater costs compared with a control group without conduct problems. ${ }^{32}$ The magnitude of this difference was about threefold, similar to our findings. Our rates of primary care (GP), police, and hospital out-patient contacts and hospital admission were high, being similar to those for a clinical sample of young people with comorbid depression and conduct disorder who were followed up until age $25-43$ years. ${ }^{21}$ However, a much higher proportion of this clinical sample had psychiatric out-patient (31\%) and in-patient (27\%) contact compared with our community-based sample.

\section{Methodological issues}

As recommended by Bernfort et al in their review of societal costs of $\mathrm{ADHD},{ }^{33}$ this study overcomes a number of the limitations of previous work. In particular, many studies have used clinically referred samples or relied on health insurance databases which may not be representative of all children in the community with these difficulties or characteristics. Similarly, cross-sectional studies describing service use by adults with ADHD do not generalise fully as these reflect a subgroup where childhood ADHD has persisted. Additionally, Bernfort et al recommended that more information was required to disentangle the effects of hyperactivity and conduct problems; ${ }^{33}$ few studies have simultaneously addressed hyperactivity and conduct problems. Another strength of our study is that it is one of the few to include criminal justice costs. ${ }^{11}$

However, the work also has a number of limitations. The sample size is small, the study was set in one relatively socioeconomically deprived geographical area, and the role of other comorbidities was not examined. In particular, the findings do not generalise to children with high levels of comorbid anxiety or depression symptoms. Although information about service use was based on self-report, previous studies have shown that service use information collected through the CSRI correlates well with case registry data ${ }^{20}$ and with primary care case notes. ${ }^{34}$ As the focus was on resource use since the age of 18 years, earlier costs relating to education services and social or residential care were not included. Although we did not have precise information about duration of prison stays, sensitivity analyses found little change in the associations between baseline characteristics and follow-up costs when we examined different assumptions. We did not collect information relating to criminal justice contact within the past 6 months. Additionally, data constraints meant that we could not assess wider societal costs, such as family-borne or employerborne costs, lost productivity, costs related to driving or accidents, undetected crimes or the impact on victims of crime.

\section{Clinical and research implications}

Across all baseline groups, there were high early adulthood levels of use of A\&E services, as well as general hospital in-patient admissions. The latter finding is striking in this young adult age group and might reflect their vulnerability to other physical health risks, limited uptake of health promotion opportunities and residence in a socioeconomically deprived part of London. In comparison to the high levels of use of general health services, the use of mental health services was low.

In terms of implications for those planning or commissioning services, our findings are relevant in today's context, as service use patterns for adults in 2002-2004 are likely to be similar to those observed today. The implications of the study's findings for service planning are therefore likely to be valid for some years to come. Cohorts of children with hyperactivity and conduct problems that are similar to those described here and who have used a similar set of children's services will be coming through to adult general and mental health services over this period. As the move towards intervention (including prevention approaches for behaviour problems) at a younger age in children's services has been more recent, ${ }^{35}$ it is likely to take at least $10-15$ years for the effects of such changes to be felt in adult services.

Recognition of ADHD-type problems in the sample was limited during both childhood and early adulthood, as demonstrated by lack of receipt of specific medication for ADHD. There is an increasing body of literature to suggest that improved recognition and the provision of effective treatment for ADHD could improve outcomes. ${ }^{30}$ In particular, data suggest that treatment for ADHD reduces the rate of criminality ${ }^{36}$ and hence potentially reduces criminal justice costs.

In terms of implications for clinicians, our findings suggest that general health and criminal justice services should be prepared for presentations from young adults who may have ongoing needs related to mental health problems in their childhood. Professionals based in these services should be alert to the presence of hyperactivity and inattentive symptoms, particularly where these have been in combination with early childhood conduct problems, and be able to refer to other services appropriately.

These findings add to our understanding about the longitudinal course of childhood behaviour problems and can help to inform policy about the potential utility of early identification and interventions. They highlight that early childhood conduct problems are particularly associated with increased healthcare and criminal justice costs in adulthood. In terms of research implications, studies investigating costs associated with ADHD should take comorbid conduct problems into account.

\section{Funding}

Data collection described here was funded by the Medical Research Council. K.S. is partly funded by the NIHR Collaborations for Leadership and Applied Health Research and Care (CLAHRC) in Nottinghamshire, Derbyshire, and Lincolnshire. 
Francesco D'Amico, PhD, Personal Social Services Research Unit, London School of Economics and Political Science; Martin Knapp, PhD, Personal Social Services Research Unit, London School of Economics and Political Science, and Centre for the Economics of Mental and Physical Health, King's College London, Institute of Psychiatry; Jenr ( London School of Economics and Political Science, and Personal Social Services Research Unit, University of Kent; Seija Sandberg, MD, FRCPsych, Mental Health Sciences Unit, University College London; Eric Taylor, MB, FRCPsych(Hon), Department of Child and Adolescent Psychiatry, King's College London, Institute of Psychiatry; Kapil Sayal, MRCPsych, PhD, Division of Psychiatry \& Applied Psychology, Institute of Mental Health, University of Nottingham, UK

Correspondence: Kapil Sayal, Division of Psychiatry \& Applied Psychology, University of Nottingham, E Floor, South Block, Queen's Medical Centre, Nottingham NG7 2UH, UK. Email: kapil.sayal@nottingham.ac.uk

\section{References}

1 Barkley RA, Fischer M, Smallish L, Fletcher K. The persistence of attentiondeficit/hyperactivity disorder into young adulthood as a function of reporting source and definition of disorder. J Abnorm Psychol 2002; 111: 279-89.

2 Klein RG, Mannuzza S, Olazagasti MA, Roizen E, Hutchison JA, Lashua EC, et al. Clinical and functional outcome of childhood attention-deficit/ hyperactivity disorder 33 years later. Arch Gen Psychiatry 2012; 69: 1295-303.

3 Biederman J, Monuteaux MC, Mick E, Spencer T, Wilens TE, Silva JM, et al. Young adult outcome of attention deficit hyperactivity disorder: a controlled 10-year follow-up study. Psychol Med 2006; 36: 167-79.

4 Rasmussen P, Gillberg C. Natural outcome of ADHD with developmental coordination disorder at age 22 years: a controlled, longitudinal, communitybased study. J Am Acad Child Adolesc Psychiatry 2000; 39: 1424-31.

5 Knapp M, King D, Healey A, Thomas C. Economic outcomes in adulthood and their associations with antisocial conduct, attention deficit and anxiety problems in childhood. J Ment Health Policy Econ 2011; 14: 137-47.

6 Chan E, Zhan C, Homer CJ. Health care use and costs for children with attention-deficit/hyperactivity disorder: national estimates from the medical expenditure panel survey. Arch Pediatr Adolesc Med 2002; 156: 504-11.

7 Guevara J, Lozano P, Wickizer T, Mell L, Gephart H. Utilization and cost of health care services for children with attention-deficit/hyperactivity disorder Pediatrics 2001; 108: 71-8.

8 Swensen AR, Birnbaum HG, Secnik K, Marynchenko M, Greenberg P, Claxton A. Attention-deficit/hyperactivity disorder: Increased costs for patients and their families J Am Acad Child Adolesc Psychiatry 2003; 42 : 1415-23.

9 Sayal K, Ford T, Goodman R. Trends in recognition and service use for attention deficit/hyperactivity disorder in Britain, 1999-2004. Psychiatr Serv 2010; 61: 803-10.

10 Snell T, Knapp M, Healey A, Guglani S, Evans-Lacko S, Fernandez J, et al. Economic impact of childhood psychiatric disorder on public sector services in Britain: estimates from national survey data. J Child Psychol Psychiatry 2013; 54: 977-85.

11 Doshi JA, Hodgkins P, Kahle J, Sikirica V, Cangelosi MJ, Setyawan J, et al. Economic impact of childhood and adult attention-deficit/hyperactivity disorder in the United States. J Am Acad Child Adolesc Psychiatry 2012; 51: 990-1002.

12 Fischer M, Barkley RA, Smallish L, Fletcher K. Young adult follow-up of hyperactive children: self-reported psychiatric disorders, comorbidity, and the role of childhood conduct problems and teen CD. J Abnorm Child Psychol 2002; 30: 463-75.

13 Sayal K, Goodman R, Ford T. Barriers to the identification of children with attention deficit/hyperactivity disorder. J Child Psychol Psychiatry 2006; 47 744-50.
14 Taylor E, Sandberg S, Thorley G, Giles S. The Epidemiology of Childhood Hyperactivity. Oxford University Press, 1991.

15 Rutter M, Tizard J, Yule W, Graham P, Whitmore K. Research report: Isle of Wight studies, 1969-1974. Psychol Med 1976; 6: 313-32.

16 Taylor E, Chadwick O, Heptinstall E, Danckaerts M. Hyperactivity and conduct problems as risk factors for adolescent development. J Am Acad Child Psychiatry 1996; 35: 1213-26.

17 Moyá J, Stringaris AK, Asherson P, Sandberg S, Taylor E. The impact of persisting hyperactivity on social relationships: a community-based, controlled 20-year follow-up study. J Atten Disord 2014; 18: 52-60.

18 Wechsler, D. Manual for the Wechsler Intelligence Scale for Children-Revised. Psychological Corporation, 1974.

19 Beecham, JK, Knapp, MRJ. Costing psychiatric interventions. In Measuring Mental Health Needs (2nd edn) (ed. G Thornicroft): 200-24. Gaskell, 2001.

20 Mirandola M, Bisoffi G, Bonizzato $\mathrm{P}$, Amaddeo F. Collecting psychiatric resources utilisation data to calculate costs of care: a comparison between a service receipt interview and a case register. Soc Psychiatry Psychiatr Epidemiol 1999; 34: 541-7.

21 Knapp M, Mccrone P, Fombonne E, Beecham J, Wostear G. The Maudsley long-term follow-up of child and adolescent depression: 3. Impact of comorbid conduct disorder on service use and costs in adulthood. Br J Psychiatry 2002; 180: 19-23.

22 Department of Health. NHS Reference Costs 2009-10. Department of Health, 2010.

23 Curtis, L. Unit Costs of Health and Social Care 2010. Personal Social Services Research Unit, University of Kent, 2010.

24 Harries, R. The Cost of Criminal Justice. Home Office Research Findings No. 103. Home Office, 1999.

25 Ministry of Justice. Costs Per Place and Costs Per Prisoner by Individual Prison: National Offender Management Service Annual Report and Accounts 2010-11 (Management Information Addendum, Information Release) Ministry of Justice, 2011.

26 Home Office. Prison Statistics England and Wales 2002. TSO (The Stationery Office), 2003 (http://www.archive2.official-documents.co.uk/document/ cm59/5996/5996.pdf).

27 Harman, HH. Modern Factor Analysis (3rd edn revised). University of Chicago Press, 1976

28 Rubin, DB. Multiple Imputation for Nonresponse in Surveys. J. Wiley \& Sons, 1987

29 Prendergast M, Taylor E, Rapoport JL, Bartko J, Donnelly M, Zametkin A, et al. The diagnosis of childhood hyperactivity. A U.S.-U.K. cross-national study of DSM-III and ICD-9. J Child Psychol Psychiatry 1988; 29: 289-300.

30 Shaw M, Hodgkins P, Herve C, Young S, Kahle J, Woods A, et al. A systematic review and analysis of long-term outcomes in attention deficit hyperactivity disorder: effects of treatment and non treatment. BMC Med 2012; 10: 99.

31 Leibson CL, Katusic SK, Barbaresi WJ, Ransom J, O'Brien PC. Use and costs of medical care for children and adolescents with and without attention-deficit/ hyperactivity disorder. JAMA 2001; 285: 60-6.

32 Scott S, Knapp M, Henderson J, Maughan B. Financial cost of social exclusion: follow up study of antisocial children into adulthood. BMJ 2001; 323: $191-4$.

33 Bernfort L, Nordfeldt S, Persson J. ADHD from a socio-economic perspective. Acta Psychiatr Scand 2008; 97: 239-44.

34 Patel A, Rendu A, Moran P, Mann A, Knapp M. A comparison of two methods of collecting economic data in primary care. Family Practice 2005; 22, 323-7.

35 Scott S. National dissemination of effective parenting programmes to improve child outcomes. Br J Psychiatry 2010; 196: 1-3.

36 Lichtenstein P, Halldner L, Zetterqvist J, Sjölander A, Serlachius E, Fazel S, et al. Medication for attention deficit-hyperactivity disorder and criminality. N Engl J Med 2012; 367: 2006-14. 